\title{
Quality management: the challenges of regional governance in West Africa
}

\author{
Loukoumanou Osseni $^{1}$, Abdérafi Charki ${ }^{2, \star}$, Fadel Kebe ${ }^{3}$, Gilles Calchera ${ }^{4}$, Luc Martin ${ }^{4}$, and Georges Bonnier ${ }^{5}$ \\ 1 Metrology and Quality Control Agency of Benin (ABMCQ), Face aux bureaux de la voirie urbaine de Cotonou, \\ Akpakpa, Cotonou, Benin \\ 2 University of Angers, ISTIA, 62 avenue Notre Dame du Lac, 49000 Angers, France \\ 3 UCAD, ESP, BP: 5085 dakar-fannn, Dakar, Senegal \\ ${ }^{4}$ CIRAD, avenue Agropolis, 34398 Montpellier Cedex 5, France \\ 5 Retired, CNAM INM-LNE, 61 rue du Landy, 93210 La Plaine St Denis, France
}

Received: 5 August 2015 / Accepted: 6 November 2015

\begin{abstract}
With a total area of $3509600 \mathrm{~km}^{2}$ and a population of over 80340000 people, the eight WAEMU countries (the West Africa Economic and Monetary Union) have many products to offer the international market. These products can be classified into three categories: fishery products, agricultural products, and agro-industrial products resulting from the processing in the first two categories. Despite the real independence of these categories, they share a common thread: efficient quality management. The crux of the matter is efficient quality management which denotes both effective and efficient management of the products. While all the theories of efficiency acknowledge a border between effectiveness and efficiency and highlight the complementarity of the two concepts, it is nonetheless interesting to note that the Russian language combines the two concepts into a single word: "effectivnost". The efficiency of a quality infrastructure is determined by both its effectiveness and its efficiency since a quality product is one that meets the standards in place, has a number of inherent characteristics that fulfil stated requirements, and can be sold within budget limits set by the consumer. In other words, quality must be managed at a restricted cost so that it is not a source of increased production costs. The formal ratification of the SOAMET (West African Secretariat of Metrology), the NORMCERQ (Regional Body of Standardization, Certification and Quality Promotion) and the SOAC (Regional Body of Accreditation) by the eight WAEMU countries through the signing of Regulation No. 01/2005/CM/UEMOA (Scheme for the Harmonization of the Activities of Accreditation, Certification, Standardization and Metrology in the WAEMU) is a very positive step. Nevertheless, both the successful implementation of this regulation and the quality of work that will derive from these organizations depend on the quality of the human factor, i.e. the competence of the people involved. The CAFMET is in a position to help solve what amounts to an equation with several unknowns. Indeed, the CAFMET has an internationally recognized expertise that continues to demonstrate its value to international metrology and standardization authorities.
\end{abstract}

Keywords: WAEMU, Quality management, metrology, SOAC, NORMCERQ, SOAMET, West Africa, CAFMET

\section{Introduction}

\subsection{Presentation of the WAEMU}

The WAEMU (West African Economic and Monetary Union) [1] is a sub-regional organization that works towards the economic integration of its Member States, by strengthening economic activities and competing in the context of an open and competitive market and of a rationalized and harmonized legal environment.

It was created in Dakar (Senegal) on January 10, 1994. The head office is in Ouagadougou (Burkina Faso). The

* Correspondence: abderafi.charki@univ-angers.fr total area covers some $3509600 \mathrm{~km}^{2}$ and the population exceeds 80340000 .

\subsection{Products that could be exportable from the WAEMU}

The WAEMU countries abound in a wide range of resources. Ivory Coast, for example, has a number of annual crops, notably coffee and cocoa (indeed Ivory Coast is one of the top exporters worldwide of these two products). If the Ivorian economy is based principally on agriculture because of the hot humid climate, the industry sector contributes to $20 \%$ of the GDP, and the tertiary sector to $50 \%$ 
of the GDP. The Ivory Coast has significant oil reserves, plus a few more minor mineral resources; it also produces electricity, part of which is sold to neighboring countries. Ivory Coast also has wood too. In Senegal are found salt and fishery products, in Togo and Benin shrimps, pineapples, shea and cashew nuts, in Mali gold and cotton, and in Niger phosphate, meat and onions. Cotton is also grown in most of these countries.

It is important to mention here that the transformation of these products begins in the WAEMU space. The fundamental issue is to ensure the access of the products to the global market. To do this, we need to ensure their quality via a quality infrastructure in accordance with today's requirements.

\subsection{State of the WAEMU quality infrastructure}

To give West African sub-region business a competitive edge, one has to solve the question of the quality infrastructure pillars at regional level. In accordance with what we stated above, this chapter will describe the state of the different WAEMU quality infrastructure pillars. We will focus on standardization, inspection, analysis and testing, certification and accreditation. Approaches will be proposed for the establishment of a quality infrastructure in the ECOWAS (Economic Community of West African Countries) [2]. Research has shown that inspection structures, testing and analysis laboratories and legal metrology services have existed in the WAEMU Member States for many years. However, the test, inspection and verification results often fail to achieve international recognition due to a lack of accredited laboratories. While efforts are being made to steer laboratories towards accreditation, a lack of financial resources linked to difficult procedures and high accreditation costs are obstacles to the success of the endeavor.

Despite these difficulties, a few laboratories have succeeded in becoming accredited, often with the help of international cooperation. Their problem is now to maintain and to renew their accreditation. For example, the Benin mass calibration laboratory, ISO 17025 [3] accredited since 1 April 2011 at a cost of $€ 19300$ (12660800 CFA Francs), has set its calibration costs at 10000 CFA Francs. Indeed, this laboratory needs a calibration volume of 1267 weights in order to attract the resources necessary for the renewal of its accreditation. This requires a fleet of at least 422 weights. Unfortunately, the fleet of weights in the Benin laboratory comprises less than 115 weights. According to this analysis, the laboratory cannot afford accreditation. In the interests of profitability, a strategy to increase the number of calibration weights is both necessary and logical. This is how we should analyze and assess the reforms introduced by the WAEMU - turning this laboratory into a regional calibration laboratory that serves as a sub-regional tool.

\subsection{Reforms introduced by the WAEMU}

In order to ensure the coherence of the Member States' quality policies with regard to the international context and promote quality, the WAEMU has created regional organizations (listed below) that are assigned to the technical, scientific and management tasks involved. This strategy aims to equip the WAEMU space with all the pillars of a quality infrastructure. The regional bodies are:

- SOAC - West African Accreditation System - a regional accreditation organization;

- NORMCERQ - a regional organization for Standardization, Certification and Quality Promotion;

- SOAMET - West African Metrology System - a regional metrology organization.

Complementing these three bodies is the Regional Committee on Quality (CREQ), which has been created to assist the Commission in the implementation of the Community Policy on Quality.

The aim of creating these structures is not only to reduce the cost of quality in the WAEMU space but also to harmonize procedures and perceptions in order to facilitate the mutual recognition of certificates issued in the different countries.

The Quality technical infrastructures and the CREQ are tasked with the harmonization and the mutual recognition of technical standards as well as of the approval and certification procedures set out by the WAEMU Convention and applied within the Member States.

For this purpose, they are responsible for:

- managing activities of scientific and technical expertise required for the harmonization and the consolidation of these fields;

- continuing the development of scientific and technical expertise in these fields in order to move towards harmonization across the Member States;

- ensuring the data collection and analysis in each field, as well as the distribution of ensuing reports;

- evaluating the existence and quality of the legislation, of standardization and of the conformity evaluation systems of the Member States;

- making recommendations for the upgrading of texts, technical regulations, standards and conformity evaluation systems necessary for the efficient functioning of the WAEMU Common Market;

- promoting networking between testing and calibration laboratories in the WAEMU and recommending any measures helpful for the consolidation of their competence;

- establishing and coordinating in collaboration with the Member States a community network of information and observation;

- receiving draft legislation, technical regulations, standards, and conformity evaluation systems in preparation within the WAEMU Member States and ensuring distribution to all countries for comment;

- drawing up an inventory of the rules, requirements and standards eligible for immediate and mutual admission 
by the Member States to facilitate the free movement of goods and services within the WAEMU;

- providing the WAEMU authorities and the Member States with reliable information to facilitate the formulation and implementation of the policies in the fields specified in Article 3 [4] above;

- giving an opinion, if necessary, to the Commission through the measures provided in Chapter 2, Heading III [4] of this regulation relating to information and notification procedures;

- promoting the establishment of a close relationship between the WAEMU, the Member States and the regional and international organizations that exist in these fields.

Regulation No. 03/2010/CM/UEMOA [4] of 21 June 2010 governs the creation of these organizations. It includes the scheme of harmonization for the accreditation, certification, standardization and metrology activities within the WAEMU.

\section{Purpose and scope of the regulation}

\subsection{Purpose}

Regulation No. 03/2010/CM/UEMOA relating to the harmonization scheme of the accreditation, certification, standardization and metrology activities within the WAEMU sets out the definition of the scheme. The implementation of this scheme is intended to promote:

- the free movement of goods and services both within the WAEMU Community and on the International Market, eliminating inappropriate or unnecessary trade barriers;

- the mutual recognition of national regulations and standards within the community and the increase of competitive goods and services on the markets through the creation of a favorable environment for their free movement;

- the enjoyment of the rights and the observation of the obligations of Member States under the terms of the agreements of the World Trade Organization (WTO) and the other cooperative conventions;

- creativity and innovation, the development of trade in goods and services covered by intellectual property rights, the advancement of sustainable development, and consumer protection;

- the strengthening of the Member States' capacity to develop and apply legislative texts on accreditation, certification, standardization and metrology in order to enhance quality;

- the participation of the WAEMU Member States in the activities of the regional and international standardization, accreditation and metrology organizations.

\subsection{Scope}

This regulation applies to the technical activities designed to ensure the quality of goods and services, in particular the standards, technical regulations, compliance assessment procedures, accreditation and authorization procedures and metrology within the WAEMU.

\subsection{General compliance principles}

In order to ensure the free movement of goods and services within the WAEMU and to improve opportunities in international trade, the Member States implement, for all fields concerned by this harmonization scheme, the international guidelines concerning Technical Barriers to Trade (TBT) as defined by the WTO agreements. In accordance with these principles, the Member States shall:

- avoid developing, passing or enforcing standards, technical regulations, accreditation procedures, compliance assessment procedures or metrology measures deemed unnecessary within the WTO agreements on Technical Barriers to Trade (TBT);

- identify and eliminate definitively said barriers to the free movement of goods and services;

- grant other Member States' goods and services (as regards standards-related measures and authorization and metrology procedures) a national treatment as favorable as for similar goods and services in the other countries;

- prepare, pass, enforce and maintain measures relating to standardization, authorization procedures and metrology such that their legitimate objectives are achieved;

- adopt compatible methods and harmonized procedures in order to determine, report and eliminate the barriers identified by an appropriate community information system.

\section{The West African accreditation system - SOAC}

\subsection{Principle of mutual recognition of conformity assessment}

The accreditation activities within the WAEMU come under the SOAC. The SOAC ensures their compliance with the international organizations' requirements.

Each Member State acknowledges the compliance assessment organizations of other Member States as equivalent to its own provided appropriate guarantees are provided, in particular where these organizations and procedures are accredited by the SOAC or have been assessed according to a procedure or system verified and approved by the SOAC.

\subsection{Consolidation of the compliance assessment}

The Member States create and consolidate their compliance assessment systems, which must then be admitted to SOAC accreditation. 
The regional and national agencies involved in the accreditation and compliance assessment activities must submit to the guidelines and standards of such international standardization bodies as, for example, the International Organization for Standardization (ISO) and the International Electrotechnics Commission (IEC).

\section{A regional organization for standardization, certification and quality promotion}

\subsection{Harmonization of standards activities}

The Member States create their own national institutions for standardization where none such exist, harmonize their practices for setting up standards and develop their technical and legal abilities in accordance with international guidelines. They must promote and apply the technical regulations and standards in compliance with these same international principles in order to ensure appropriate protection for their populations and for the environment.

\subsection{Establishment of technical specifications}

Technical specifications are formulated in order to avoid the technical barriers to trade or other barriers or measures deemed unjustified in the WTO agreements on Technical Barriers to Trade (TBT).

The Member States impose consistent, simple and clear technical specifications keeping the administrative and implementation impact/costs/workload as low as possible.

They ensure their mutual information by using the notification procedures established by this regulation in order to harmonize technical limitations within the WAEMU.

\subsection{Contribution to the International bodies' workshops}

The Member States ensure that their bodies belong to internationally recognized standardization bodies, in particular the African Organization for Standardization (ARSO), the African Electrotechnics Standardization Commission (AFSEC), the International Organization for Standardization (ISO) and the International Electrotechnics Commission (IEC). Their bodies are represented at these international standardization bodies by NORMCERQ (where their status permits). The national standardization bodies harmonize their positions within NORMCERQ.

\subsection{Documentation and information}

The Member States adopt compatible management systems for documentation and information relating to standardization and quality management in order to facilitate communication between the national standardization bodies, NORMCERQ and the corresponding international bodies.

\subsection{Popularization of the standardization activities}

The Member States make their standardization and quality management activities known to their WAEMU partners in particular by means of seminars, advertising, publication of interviews and opinion reports, participation in trade shows, and creation of national awards and national quality promotion organizations.

\subsection{Formulation of standards and technical regulations}

The Member States coordinate the activities of the various ministries, departments and services involved in formulating standards and technical regulations in line with the community harmonization scheme outlined by this regulation.

Via a standardization program, community standards are formulated and passed by NORMCERQ then approved by the WAEMU Commission. The formulation of community standards is carried out in accordance with a procedure imposed by the Commission through the enforcement regulation.

The council of Ministers can institute technical regulations based on community standards. It can also institute community technical regulations based on standards set by international standardization bodies, following notification of NORMCERQ.

\subsection{Collection of national standards}

NORMCERQ centrally collects and manages national standards, which Member States are obliged to submit, and receives their annual standardization programs.

NORMCERQ briefs the Member States in order to align the mutual recognition of national standards and, in the event of a consensus, puts forward a proposal for community approval.

For community standards projects in progress, NORMCERQ implements the intra-community information procedures outlined in Heading IV of this regulation, designed to enable all Member States to assert their interests and/or their wish to participate in the workshops concerned.

\subsection{Community compliance marks}

The commission may propose to the Member States the creation of community compliance marks. The commission carries out the protection formalities involved, and defines the conditions of their use and the related fees. 


\subsection{Towards quality management}

The Member States:

- apply harmonized standards and procedures for the inspection and analysis of goods and services exchanged within the WAEMU so that results can be interpreted and coordinated easily and uniformly;

- establish standards for quality management systems that are acceptable and reinforce the quality assurance capacities of goods and services exchanged within the WAEMU;

- use harmonized documents for the quality assessment of goods and services exchanged within the WAEMU;

- facilitate checks and movement of goods within the WAEMU in order to improve exchanges in collaboration with the Customs Administration and the other relevant departments.

Some community measures on inspection and market surveillance may be subject to a specific text.

\section{The West African metrology system (SOAMET)}

\subsection{Role of the SOAMET}

The SOAMET contributes to the definition and implementation of community policy on metrology, overseeing its development in the WAEMU and the establishment of an infrastructure that meets international standards. For this purpose it coordinates activities on metrology in the WAEMU.

\subsection{Participation in the international bodies' workshops}

The Member States are members of international bodies and take the measures necessary for the effective participation of their metrology bodies in these workshops. The Member States may be represented by the SOAMET (if the statute of the body concerned permits). They harmonize their positions.

\subsection{Use of international systems}

The Member States base their internal metrology on the Meter Convention, the International System of Units (SI) and certain measures established by the International $\mathrm{Bu}-$ reau of Weights and Measures (BIPM) and by the International Organization of Legal Metrology (OIML).

The Member States adopt the International System of Units (SI) and rapidly set about developing the tools and strategies needed to adapt their national structures to resulting technological changes, thus ensuring the WAEMU measurement systems meet international requirements.

The Member States ensure traceability on their metrology in accordance with BIPM procedures.
For their activities on legal metrology, the Member States comply with the OIML recommendations and documents.

\section{Other measures covered by the regulation}

\subsection{Mutual recognition}

The Member States opt for the principle of mutual recognition within the WAEMU as a flexible and gradual way of implementing the arrangements intended to promote free movement of goods and services and reduce barriers.

Within the common market, they ensure the existence of a coherent blend of harmonized legislation, standards and compliance tools.

A Member State may be exempted from the requirement of free movement of goods and services only under the conditions set out in Article 79 [1] of the WAEMU Convention.

The mutual recognition on quality or on compliance of goods and services between the Member States operates at three levels:

- the recognition of technical regulations, standards and specifications;

- the recognition of assessment compliance procedures, which implies that each Member State accepts the assessment procedures and the evaluation reports of other Member States as equivalent to its own;

- the recognition of the results of assessment compliance procedures, which implies that each Member State acknowledges the test results, the compliance certificates, the compliance marks, and the compliance inspections of the other Member States.

\subsection{Equivalence and principle of national treatment}

Each Member State accepts into its territory any good or service that meets a technical rule or assessment compliance procedure adopted by another Member State and considers it equivalent to its own, when the exporting state, with the cooperation of the importing state, proves that good is legally manufactured or marketed in its own territory.

At the request of the exporting state, an importing state will give written notice, in accordance with information forms agreed between the Member States in Section 2 above, stating the reasons why it does not accept a technical rule or assessment compliance procedure of the exporting state as being equivalent.

In the event of divergences, the Member States enter into discussions in order to assess the barrier to free movement and allow the Member States to prepare and harmonize technical criteria or assessment compliance procedures for the good or service concerned. 


\subsection{Precautionary principle and risk assessment}

To meet its own legitimate objectives, each Member State may undertake risk assessment and either maintain or put in place prohibitions as barriers to the free movement of goods or services.

A Member State that carries out a risk assessment will take into account:

- similar risk assessments carried out by international bodies;

- scientific evidence and all technical references available;

- technical implementation of the goods or service concerned;

- comprehensive and specific uses planned for the goods or services;

- production processes or methods capable of altering the characteristics of the goods or services;

- utilization methods, compliance assessments and environmental parameters.

The Member States must make available any relevant documentation on risk assessment procedures they have taken into account in determining their protective prohibition or restriction measures.

\section{The CAFMET (African Committee of Metrology) and its place in the implementation of the WAEMU reforms}

The performance of a sub-regional quality infrastructure presented above, largely depends on the quality of the workforce that manages it. That is why the creation of the CAFMET (African Committee of Metrology) [5] and its actions are factors that increase the likelihood of meeting the challenge of regional governance, required for the quality management of goods from the WAEMU zone intended for the international market.

The CAFMET will without any doubt help solve this equation with several unknowns thanks to its internationally recognized expertise, which continues to prove its worth to international metrology and standardization bodies. All countries of West Africa need to develop more and to maintain the competences in metrology and in quality management. That last point is a great challenge!

\section{Conclusion}

In today's world, quality management is the only route possible for African countries wishing to meet the challenge of globalization. While it is true that African goods need to be handled in a way that inspires consumer confidence, this aspect needs to be dealt with at the lowest possible cost. Indeed, it is because of the relatively high cost of establishing a quality infrastructure that a synergy of forces is so highly desirable.

\section{References}

1. http://www .uemoa.int/Pages/Home.aspx

2. https://www. ecowas.int/

3. ISO/IEC 17025:2005, General requirements for the competence of testing and calibration laboratories

4. https://www.wto.org

5. A. Charki, C. Ferrier, G. Bonnier, M. Berrada, E.A. Hassani, L. Osseni, Metrology in Africa : role of the CAFMET, Accreditation and Quality Assurance 4, 227 $230(2009)$ 